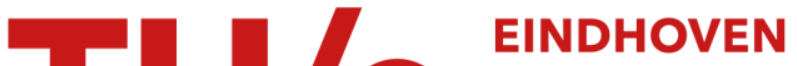 UNIVERSITY OF TECHNOLOGY
}

\section{Experimental and theoretical analysis of vacuum circuit breaker prestrike effect on a transformer}

Citation for published version (APA):

Popov, M., Smeets, R. P. P., Sluis, van der, L., Herdt, de, H., \& Declercq, J. (2009). Experimental and theoretical analysis of vacuum circuit breaker prestrike effect on a transformer. IEEE Transactions on Power Delivery, 24(3), 1266-1274. https://doi.org/10.1109/TPWRD.2009.2013383

DOI:

10.1109/TPWRD.2009.2013383

Document status and date:

Published: 01/01/2009

\section{Document Version:}

Publisher's PDF, also known as Version of Record (includes final page, issue and volume numbers)

\section{Please check the document version of this publication:}

- A submitted manuscript is the version of the article upon submission and before peer-review. There can be important differences between the submitted version and the official published version of record. People interested in the research are advised to contact the author for the final version of the publication, or visit the $\mathrm{DOI}$ to the publisher's website.

- The final author version and the galley proof are versions of the publication after peer review.

- The final published version features the final layout of the paper including the volume, issue and page numbers.

Link to publication

\section{General rights}

Copyright and moral rights for the publications made accessible in the public portal are retained by the authors and/or other copyright owners and it is a condition of accessing publications that users recognise and abide by the legal requirements associated with these rights.

- Users may download and print one copy of any publication from the public portal for the purpose of private study or research.

- You may not further distribute the material or use it for any profit-making activity or commercial gain

- You may freely distribute the URL identifying the publication in the public portal.

If the publication is distributed under the terms of Article 25fa of the Dutch Copyright Act, indicated by the "Taverne" license above, please follow below link for the End User Agreement:

www.tue.nl/taverne

Take down policy

If you believe that this document breaches copyright please contact us at:

openaccess@tue.nl

providing details and we will investigate your claim. 


\title{
Experimental and Theoretical Analysis of Vacuum Circuit Breaker Prestrike Effect on a Transformer
}

\author{
Marjan Popov, Senior Member, IEEE, René Peter Paul Smeets, Fellow, IEEE, \\ Lou van der Sluis, Senior Member, IEEE, Hans de Herdt, and Jan Declercq, Member, IEEE
}

\begin{abstract}
The work presented in this paper deals with the investigation of circuit breaker prestrike effect that occurs during energizing a distribution transformer. An experimental test setup that consists of a supply transformer, a vacuum circuit breaker (VCB), a cable and a test transformer is built, and the prestrikes in the VCB are recorded. The test transformer is a prototype distribution transformer, with installed measuring points along transformer windings in each phase. Voltage oscillations are measured along the windings and transformer terminals. The transformer is modeled by lumped parameters extracted from telegrapher's equations in discrete form.

Voltage oscillations during switching-in operations are recorded and calculated with and without a cable installed between the VCB and the transformer. Computed voltages show good agreement with the measured voltages. Described method can be used by transformer manufacturers to estimate voltage wave forms during switching or lightning, to provide useful information for insulation coordination studies, and to investigate resonance effects in transformer windings.
\end{abstract}

Index Terms-Modeling, switching tests, transformer, vacuum circuit breaker.

\section{INTRODUCTION}

$\mathbf{I}$ T IS well known that during switching highly inductive loads like transformers and motors, under specific conditions, multiple restrikes in the circuit breaker can occur. Multiple restrikes are fast voltage surges which proceed along the cable and reach transformer or motor terminals. Because of different surge impedances at terminals, a wave reflection and absorption takes place. Voltage oscillations which proceed toward windings are continuously superposed by new voltage waves from new upcoming surges. Hence, voltage waveforms along the transformer winding within a particular time interval can have very different amplitude and rate of rise. Their oscillations contain a broad frequency range which can be from a few kilohertz up to a few megahertz. These are unwanted phenomena

Manuscript received March 06, 2008; revised July 02, 2008. First published May 08, 2009; current version published June 24, 2009. This work was supported by the Dutch Scientific Foundation NWO/STW under Grant VENI, DET. 6526. Paper no. TPWRD-00147-2008.

M. Popov and L. van der Sluis are with the Faculty of Electrical Engineering, Mathematics and Computer Science, Delft University of Technology, Delft 2628CD, The Netherlands (e-mail: M.Popov@ieee.org).

R. P. P. Smeets is with KEMA, 6800 ET Arnhem, The Netherlands, and the Department of Electrical Engineering, Eindhoven University of Technology, Eindhoven, 5600 MB, The Netherlands (e-mail: Rene.Smeets@ kema.com)

H. de Herdt and J. Declercq are with Pauwels Trafo Belgium N.V., B-2800 Mechelen, Belgium (e-mail: Hans.de.Herdt@pauwels.com; J.Declercq@HansenTransmissions.com).

Color versions of one or more of the figures in this paper are available online at http://ieeexplore.ieee.org.

Digital Object Identifier 10.1109/TPWRD.2009.2013383 which cause deterioration and failure of the equipment insulation. Almost one third of all motor failures occur because of fast switching surges [1]. Switching surges which enter the windings are non-linearly distributed [2]. Besides, sometimes high inter-turn overvoltages can take place which stress the thin insulation and accelerate its failure. So far, a lot of work has been done on transformer and motor switching [3]-[9]. However, voltage transients are measured on transformer terminals and prediction of the voltage distribution along the windings is difficult to be done. In [10] a computer model for motor windings is described which is applied during sequential pole closing [11]. It is also applied for determination of inter-turn voltages during energizing a motor with a VCB [12].

Most of the time, the geometry of the windings and dimensions are not known. Furthermore, a proper model based on transformer geometry and type of windings is difficult to develop. Consideration of the frequency-dependent losses is another problem.

So far, there was successful work done on transformer modeling. In [13] and [14], a hybrid model based on transmission line theory was successfully applied to describe the wave propagation in large shell-type transformers. An accurate approach for modeling transformers and motors is done by applying the so called vector fitting [15]. This model is based on the measured frequency admittance matrix of the transformer, the elements of which are admittances measured from any provided measuring point in the transformer windings [16]. The advantage of the latter model is that it gives the possibility to use existing simulation software like EMTP.

In this work, the prestrike effect during energizing the transformer was investigated. Voltage waveforms on transformer terminals are measured and they are used as an input parameter to the transformer model. A lumped-parameter model based on discretized telegraphist's equations is applied [17]. It was found that this approach can be successfully applied for computation of voltages along the windings, even for matrices with large dimensions $(100 \times 100)$. Computations are done in frequency domain, and time domain solutions are provided by applying inverse continuous Fourier transform [18]. Measurements and computations are also done with and without a cable applied between the VCB and transformer. The computations are verified by laboratory measurements.

\section{TEST TRANSFORMER AND ITS REPRESENTATION}

\section{A. Transformer Description}

The test transformer is a three-phase layer-type transformer. However, the computation and measurements of the voltages 


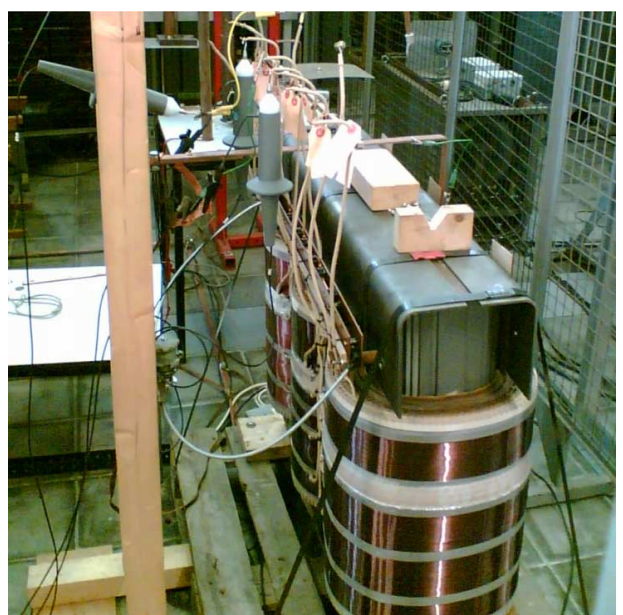

Fig. 1. Test transformer.

TABLE I

TRANSFORMER DATA

\begin{tabular}{|l|c|}
\hline \hline Transformer Power & $630 \mathrm{kVA}$ \\
\hline Transformer ratio & $15375 \mathrm{~V} / 400 \mathrm{~V}$ \\
\hline No-load losses & $770 \mathrm{~W}$ \\
\hline No-load current & $0.3 \%$ \\
\hline Number of layers (HV side) & 10 \\
\hline Number of turns in a layer & $\sim 140$ \\
\hline Inner radius of HV winding & $135.3 \mathrm{~mm}$ \\
\hline External radius of HV winding & $163.3 \mathrm{~mm}$ \\
\hline Inner radius of the LV winding & $97 \mathrm{~mm}$ \\
\hline Wire diameter & $3.0 \mathrm{~mm}$ \\
\hline Double wire insulation & $0.1 \mathrm{~mm}$ \\
\hline Distance between layers & $0.4 \mathrm{~mm}$ \\
\hline Coil's height & $425 \mathrm{~mm}$ \\
\hline \hline
\end{tabular}

along the windings is done per phase whilst other two phases are not connected to the studied phase.

The primary transformer winding consists of layers with approximately 140 turns. The transformer is equipped with special measuring points in each phase. In phase A, measuring points are installed at the 3rd and the 5th turn. In phase B, the measuring points are at the 290th and the 580th turn, and in phase $\mathrm{C}$, the measuring points are at the 444th and the 888th turn. All measuring points can be directly reached as it can be seen from Fig. 1. The most important parameters of the transformer are summarized in Table I.

\section{B. Transformer Representation}

Studied transformer is a layer-type prototype transformer particularly produced for this research. The transformer has measuring points installed in each phase. The tank and the oil are removed so that an easy access to the windings can be provided. The transformer with capacitances and inductances is represented in Fig. 2. The inductance matrix is formed by the self inductances of a group of turns and mutual inductances between the turns. The capacitance matrix is formed by capacitances between layers and capacitances from the top and the bottom of the layers to the transformer tank.

The transformer represented in Fig. 2 can be simplified by rearranging the capacitances. To do this, we will consider an

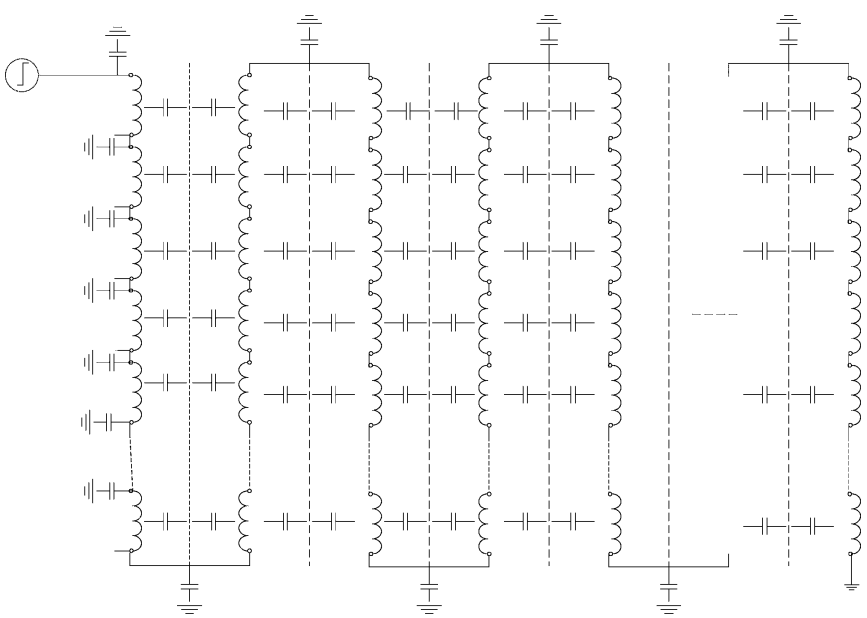

Fig. 2. Transformer capacitances and inductances.
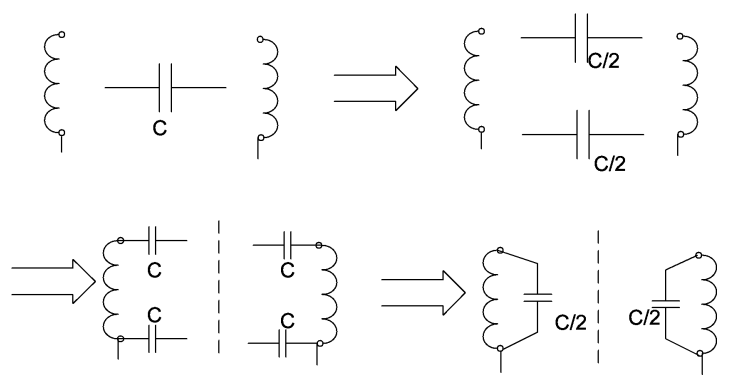

Fig. 3. Simplification of a section of the transformer.

equipotential surface between the layers [2]. In this way, one can divide a group of winding in the following way. Half of the capacitance between coils is added to the edges of the coils [19]-[21]. Then, it is assumed that there is an equipotential line in the middle of the coil, so that the capacitance between coils can be added as a cross-over capacitance at each coil with a value equal to the half of the value of the total capacitance. The description is given in Fig. 3.

Fig. 4 represents the simplification of the transformer model from Fig. 2, and Fig. 5 is the final model of the transformer. It has to be pointed out that the cross-over capacitances which belong to the first and last layer are a half of the cross-over capacitance of the other layers. Capacitances to ground in this case are small because the surface of the top and bottom of the coil is small. They are estimated as less than $1 \mathrm{pF}$.

\section{Inductance and Capacitance Matrix}

Inductances are calculated by the well known Maxwell formulas on a turn-to-turn basis [22]. The $\mathbf{L}$ matrix is formed in a way that diagonal elements of the matrix correspond to a group of turns. The off-diagonal elements are mutual inductances between different groups of turns. For simplicity in this case, the number of turns in a group is kept constant. The studied transformer has ten layers with approximately 142 turns per layer. Each layer is divided in ten groups with 14 turns per group. So, we assume that a layer consists of ten groups. So the transformer $\mathbf{L}$ matrix is of order $100 \times 100$. The capacitance matrix is built on a node-to-node basis and because the number of nodes 


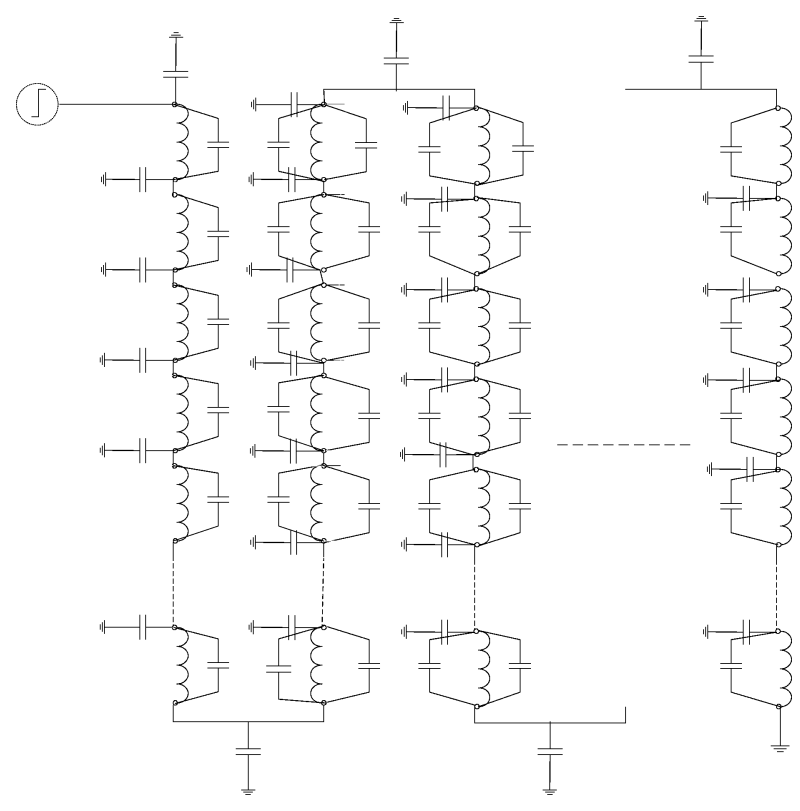

Fig. 4. Simplification of the circuit from Fig. 1.

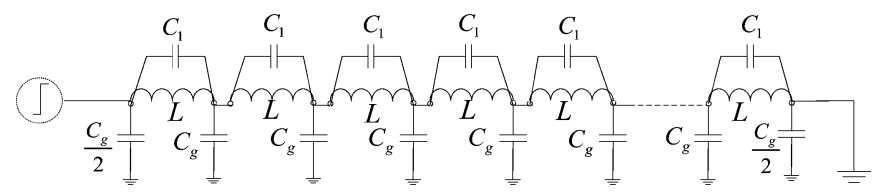

Fig. 5. Final lumped-parameter model for transformer voltage distribution studies.

$\mathrm{N}=\mathrm{B}+1$ where $\mathrm{B}$ is the number of branches represented by inductances, the capacitance matrix is of order $101 \times 101$.

Finally, by making use of the inductance matrix $\mathbf{L}$ and the capacitance matrix $\mathbf{C}$, impedance and admittance matrices $\boldsymbol{Z}$, and $\boldsymbol{Y}$ are determined [22]

$$
\begin{aligned}
\mathbf{Z} & =\left(j \omega+\sqrt{\frac{2 \omega}{\sigma \mu_{0} d^{2}}}\right) \mathbf{L} \\
\mathbf{Y} & =(j \omega+\omega \tan \delta) \mathbf{C}
\end{aligned}
$$

where

$d$ distance between layers;

$\sigma$ conductor conductivity;

$\tan \delta$ loss tangent of the insulation.

\section{TRANSFORMER MODELING}

According to [17], a general representation of $\mathrm{N}$-winding transformer can be done by discretizing the transmission line equations. The general govern equations for the voltages and currents are

$$
\begin{gathered}
\frac{d V_{i}(x)}{d x}=\sum_{j=1}^{N}-\int_{0}^{\lambda_{j}} Z_{\mathrm{ij}}(x, \beta) I_{j}(\beta) \quad i=1,2, \ldots N \\
\frac{d I_{i}(x)}{d x}=\sum_{j=1}^{N}-\int_{0}^{\lambda_{j}} Y_{\mathrm{ij}}(x, \beta) V_{j}(\beta) \quad i=1,2, \ldots N .
\end{gathered}
$$

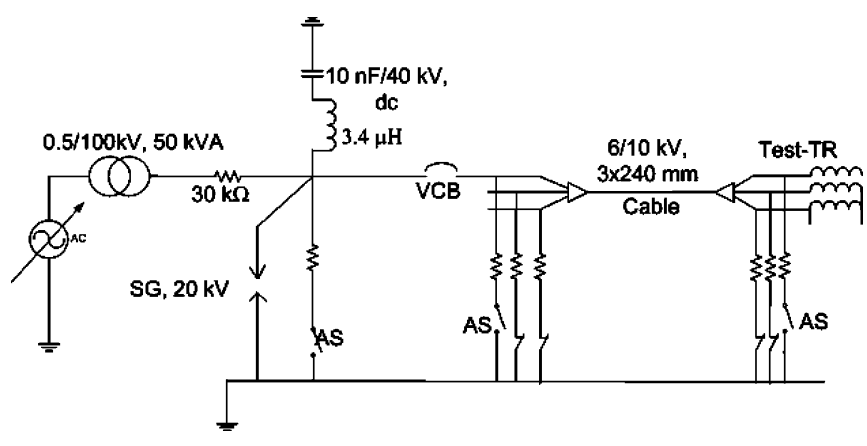

Fig. 6. Transformer switching test circuit.

Equations (2) and (3) are general equations that represent $\mathrm{N}$-winding transformer model. In (2), $I_{j}(\beta)$ is the inductive current at a distance $\beta$ down the $j$ th winding, and $Z_{\mathrm{jj}}(x, b)$ is a mutual impedance function. The self- and mutual impedance is frequency dependent, (2) is also in frequency domain, so the $V_{i}(x)$ and $I_{j}(\beta)$ are Fourier transformer of $V_{i}(x, t)$ and $I_{j}(\beta, t)$, respectively. $\lambda_{j}$ represents the length of the $j$ th winding. Because we are dealing with only one winding, the computation can be rather simplified, so the solution can be represented in a matrix form

$$
\left[\begin{array}{l}
\mathbf{I}_{\mathbf{B}} \\
\mathbf{V}^{\prime}
\end{array}\right]=\left[\begin{array}{ll}
\mathbf{A} & \mathbf{B} \\
\mathbf{C} & \mathbf{D}
\end{array}\right]\left[\begin{array}{l}
\mathbf{V}_{\mathbf{B}} \\
\mathbf{V}^{\prime}
\end{array}\right]
$$

where $\mathbf{V}_{\mathbf{B}}$ represents the set of voltages at the winding terminals, and $\mathbf{I}_{\mathbf{B}}$ represents the set of currents entering them

$$
\mathbf{V}_{\mathbf{B}}=\left[\begin{array}{c}
\mathbf{V}_{\mathbf{S}} \\
\mathbf{V}_{\mathbf{R}}
\end{array}\right], \quad \mathbf{I}_{\mathbf{B}}=\left[\begin{array}{c}
\mathbf{I}_{\mathbf{S}} \\
-\mathbf{I}_{R}
\end{array}\right] .
$$

Applying (5), one can calculate the voltages in the internal nodes as

$$
\mathbf{V}^{\prime}=(1-\mathbf{D})^{-1} \mathbf{C} \mathbf{V}_{\mathbf{B}} .
$$

More about derivation of (6) and corresponding submatrices A, $\mathbf{B}, \mathbf{C}$, and $\mathbf{D}$ can be found in [17]. The time domain solutions are calculated by continuous inverse Fourier transform [18].

\section{Description of the Measuring Setup}

The measuring setup is done similar to the motor switching test circuit IEC 62271-110 [23]. The supply transformer is a special laboratory transformer with a voltage ratio $0.5 / 100 \mathrm{kV}$ and nominal power of $50 \mathrm{kVA}$. Because the nominal current is $0.5 \mathrm{~A}$, only switching-in tests at different voltage levels and at low current are performed. A $30 \mathrm{k} \Omega$ resistor on the high-voltage transformer side is installed to limit the load current and protect the transformer from high currents. So the circuit is realized in a way to produce negligible current. On the high-voltage side of the supply transformer, a spark gap with a breakdown voltage of $20 \mathrm{kV}$ is installed in order to protect the circuit from high overvoltages. Furthermore, only single-phase switch-in operations are performed, so the other two phases are grounded through a grounding switch AS. The test transformer is designed in a way that during measurements in one phase, the other two phases are disconnected and the end of the measured phase is grounded. The transformer switching test circuit is shown in Fig. 6. A 


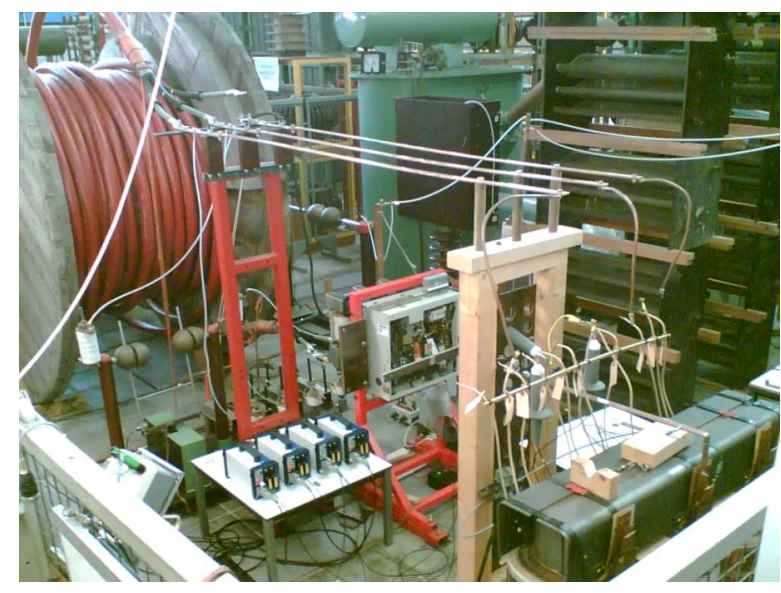

Fig. 7. Transformer switching test circuit.

TABLE II

CABLE Data

\begin{tabular}{|l|c|}
\hline \hline Resistance (at $\left.90^{\circ} \mathrm{C}, 50 \mathrm{~Hz}\right)$ & $0.161 \Omega / \mathrm{km}$ \\
\hline Reactance (at $50 \mathrm{~Hz})$ & $0.088 \Omega / \mathrm{km}$ \\
\hline Capacitance & $0.41 \mu \mathrm{F} / \mathrm{km}$ \\
\hline Length & $100 \mathrm{~m}$ \\
\hline wave travel time (measured) & $5.7 \mathrm{E}-7 \mathrm{~s}$ \\
\hline \hline
\end{tabular}

TABLE III

PERFORMED TYPES OF MEASUREMENTS

\begin{tabular}{|l|l|l|l|l|l|}
\hline & & $4 \mathrm{kV}$ & $6 \mathrm{kV}$ & $8 \mathrm{kV}$ & $12 \mathrm{kV}$ \\
\hline \multirow{2}{*}{$\begin{array}{c}\text { Phase } \\
\text { B }\end{array}$} & with cable & & $\mathrm{x}$ & $\mathrm{x}$ & \\
\cline { 2 - 6 } & no cable & & & $\mathrm{x}$ & $\mathrm{x}$ \\
\hline $\begin{array}{c}\text { Phase } \\
\mathrm{C}\end{array}$ & with cable & & & $\mathrm{x}$ & \\
\cline { 2 - 6 } & no cable & $\mathrm{x}$ & & & \\
\hline
\end{tabular}

photo of the test setup is presented in Fig. 7. During switching, a prestrike effect in the VCB takes place, so surges propagate along the cable and reach the transformer windings. The voltages are measured at the transformer terminal and at the measuring points installed along the winding.

Voltages are measured by applying $20-\mathrm{kV}$ PMK voltage probes between a specific measuring point and the ground, and currents are measured by a high frequency Pearson Electronic current probe. Both, currents and voltages are recorded by a 4-channel Nicolet Genesis transient recorder with a resolution of 14 bits and a sampling rate of $100 \mathrm{MS} / \mathrm{s}$.

Cable data provided by the manufacturer are summarized in Table II. The travel time of the wave along the cable is measured by a applying a pulse with a short rise time at the sending end of the cable, and recording the response at the receiving end.

\section{Test Results}

\section{A. VCB Switching-In Test}

Switching tests with the vacuum circuit breaker are done at different voltage levels. The voltage is changed between 4 $\mathrm{kVrms}$ and $12 \mathrm{kVrms}$ with a step of $2 \mathrm{kVrms}$. Furthermore, measurements are done with and without a cable. Table III summarizes the results of the measurements which are presented here.
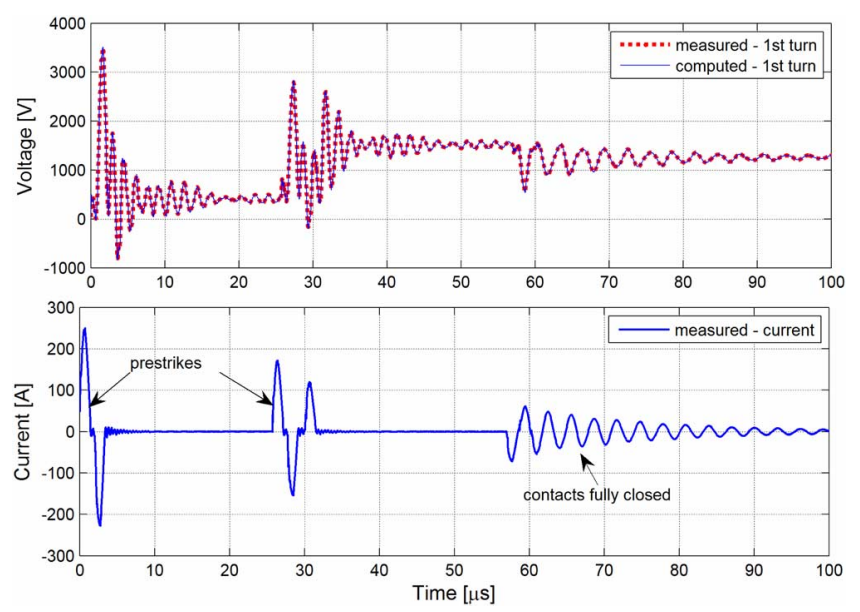

Fig. 8. Measured and computed transformer terminal voltage in phase $B$ during transformer energizing with applied voltage of $6 \mathrm{kV}$ (upper figure); measured circuit breaker current (lower figure).
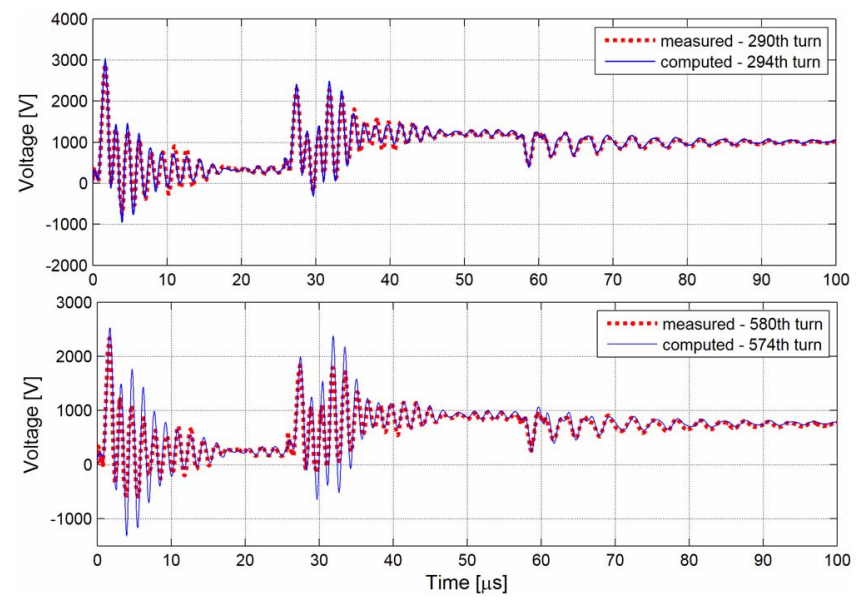

Fig. 9. Measured and computed voltages at specific turns in phase B during transformer energizing with applied voltage of $6 \mathrm{kV}$.

Fig. 8 through 12 shows the results of the case when the transformer phase B is energized by a supply voltage of 6 and $8 \mathrm{kV}$. During energizing the transformer, a prestrike occurs before the contacts physically touch each other. Fig. 8 shows the first test done with a supply voltage of $6 \mathrm{kV}$. This test is followed by two prestrikes. After approximately $25 \mu$ s from the second prestrike, the contacts fully close and the load current is established. Fig. 9 shows measured and computed voltages at specific points during $6-\mathrm{kV}$ transformer energizing.

The next test is done with a supply voltage of $8 \mathrm{kV}$, as shown in Fig. 10. In this case, two prestrikes can be seen just as in the previous case, and the duration of the prestrike current is longer. This is according to the expectations; the higher the system voltage, the higher the duration of the prestrikes.

The oscillation frequency of the prestrike current is about $280 \mathrm{kHz}$. This frequency normally depends on the source side equivalent capacitance, load side equivalent capacitance and cable inductance [8]. However, this analysis shows that this is actually the lower resonance cable frequency $f_{0}=1 /(2 \pi \tau) \approx 279.36 \mathrm{kHz}$, where $\tau=\sqrt{L C} ; L(\mathrm{H})$ and $C$ (F) are cable inductance and capacitance respectively. 

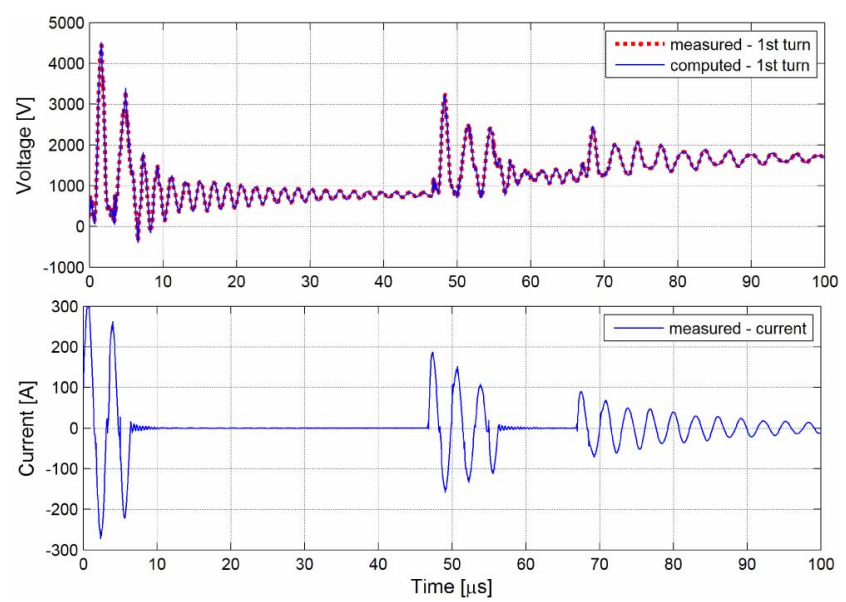

Fig. 10. Measured and computed transformer terminal voltage in phase B during transformer energizing with applied voltage of $8 \mathrm{kV}$ (upper figure); measured circuit breaker current (lower figure).
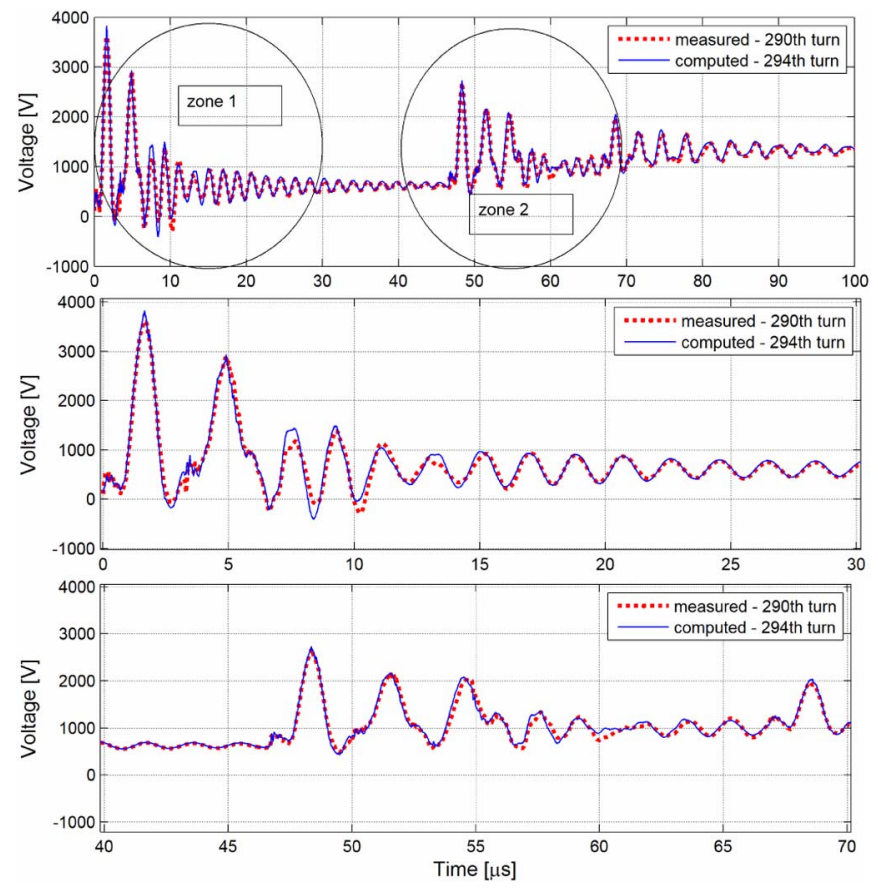

Fig. 11. Measured and computed voltages in phase B during transformer energizing with applied voltage of $8 \mathrm{kV}$ (upper figure); zone 1, first $30 \mu \mathrm{s}$ (middle figure); zone 2, 40-70 $\mu$ s (lower figure).

The oscillation frequency of the transformer voltages after the clearing of the prestrike current is approximately $500 \mathrm{kHz}$. This is the upper resonance frequency of the cable.

The amplitude of the current during second prestrike, as it can be seen from Fig. 8 and Fig. 10, has lower value than that during the first prestrike. The reason for this is that the prestrike current depends on the withstand voltage between the circuit breaker contacts. Prestrike occurs when the transient recovery voltage is greater than the withstand voltage. As the contacts approach to each other, the withstand voltage is lower and the prestrike current decreases accordingly.

In all figures, measured and computed voltages are represented. For the turn 1 which is the terminal transformer voltage,
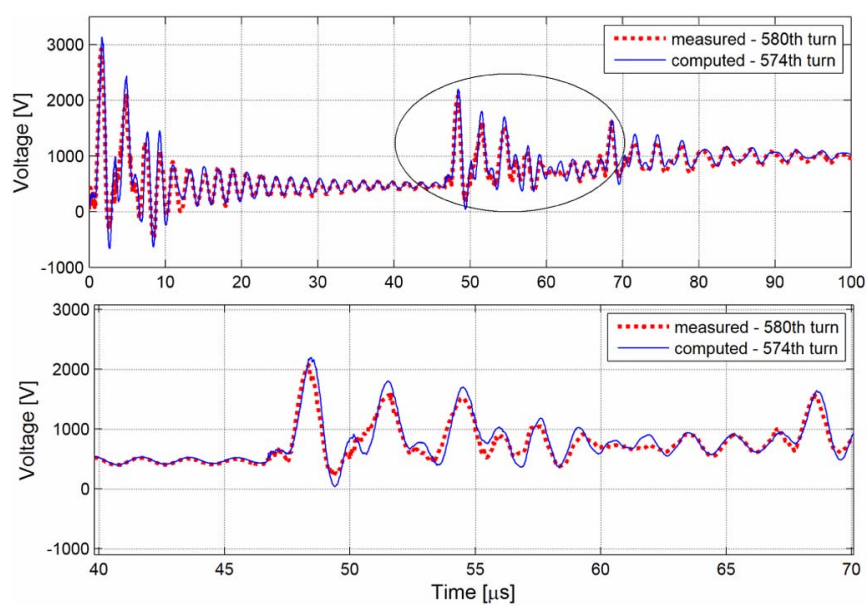

Fig. 12. Measured and computed voltages in phase B for transformer energizing with applied voltage of $8 \mathrm{kV}$ (upper figure); increased time scale between 40-70 $\mu$ s (lower figure).

there is a very good matching. From the measured voltage a numerical Fourier transform is done. The computed result is the inverse Fourier transform. This actually shows that the time domain solution is correctly obtained. This is important because the measured voltage at the transformer terminal is an input parameter for the determination of the voltage distribution in all windings. Furthermore, it can be seen that there is a good agreement between measured and computed voltages.

Fig. 11 presents measured and computed voltages for the second test with supply voltage of $8 \mathrm{kV}$ in phase B. Voltage transients in the 290th turn are measured and compared with the computed transients in the 294th turn. Fig. 11 shows the enlarged time scale for the zone 1 and zone 2 .

Also, an enlarged time scale between $40 \mu$ s and $70 \mu \mathrm{s}$ in Fig. 12 is shown for voltage transients recorded and computed in the 580th and 574th turn respectively.

Figs. 13 and 14 shows the results during transformer energizing of phase $\mathrm{C}$ with $8-\mathrm{kV}$ supply voltage. In this phase, the 444th turn and 888th turn are supplied with measuring points. The comparison shows that the measured and computed results in the 888th turn differ more during the period of reignitions than those computed for the 294th and 574th turn in phase B. This means that the error rises as the turn number increases. This is most probably because of the frequency-dependent losses which provide higher damping than the damping that results from the losses as estimated by (1).

Fig. 15 presents the results of the case when the transformer is energized without applying a cable between the circuit breaker and the transformer. The supply voltage is $4 \mathrm{kV}$. Recorded voltage in 444th turn is compared by the computed voltage in 434th turn. It can be seen that the prestrike current in this case is eliminated after half cycle.

In Fig. 16, the results of a switching test without a cable between the VCB and transformer are presented for a supply voltage of $8 \mathrm{kV}$. Solid lines in the upper and in the middle figure represent the computed results, whilst dotted lines show the measured results. The prestrike current (just as in the previous case-see Fig. 15) is damped rapidly, and the voltage decreases rapidly after arc extinction. The reason for this is that 

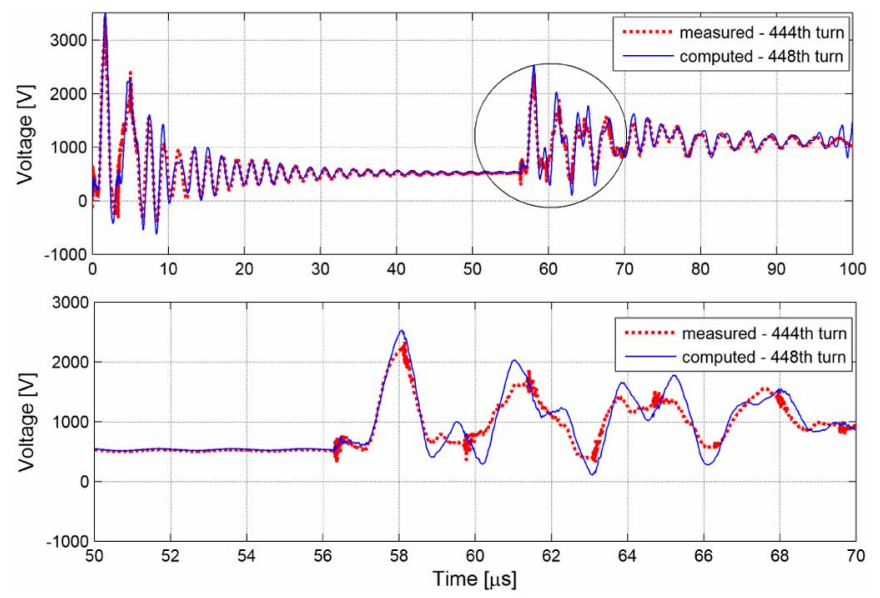

Fig. 13. Measured and computed voltages in phase $\mathrm{C}$ for transformer energizing with applied voltage of $8 \mathrm{kV}$ (upper figure); increased time scale between 50-70 $\mu$ s (lower figure).
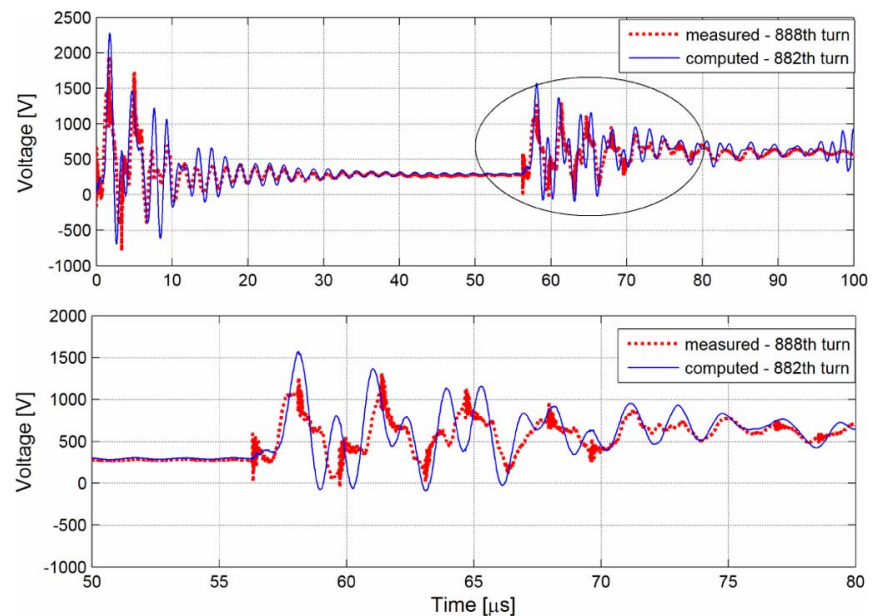

Fig. 14. Measured and computed voltages in phase $\mathrm{C}$ for transformer energizing with applied $8 \mathrm{kV}$ (upper figure); increased time scale between $50-80 \mu \mathrm{s}$ (lower figure).
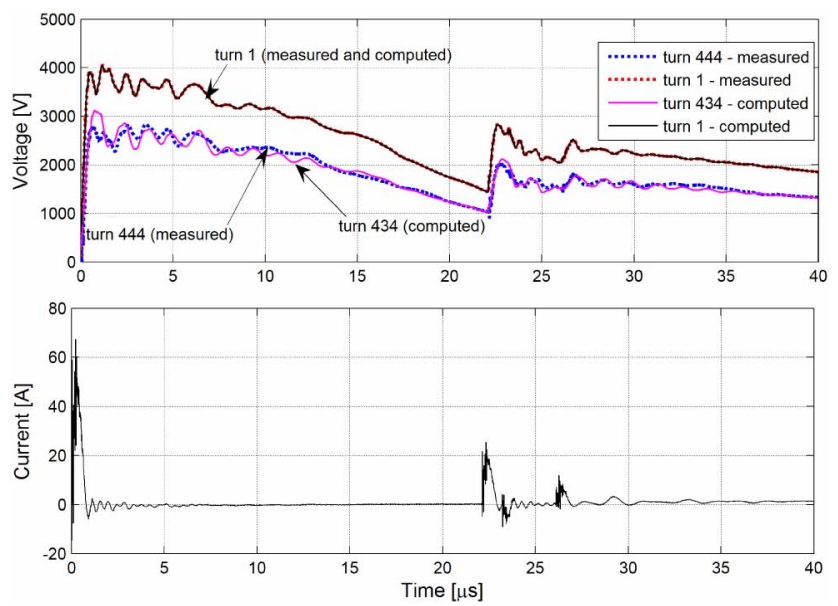

Fig. 15. Measured and computed voltages in phase $\mathrm{C}$ (upper figure); measured circuit breaker current (lower figure).

the load voltage side capacitance is very low and consists only of the transformer bushing capacitance and busbar capacitance
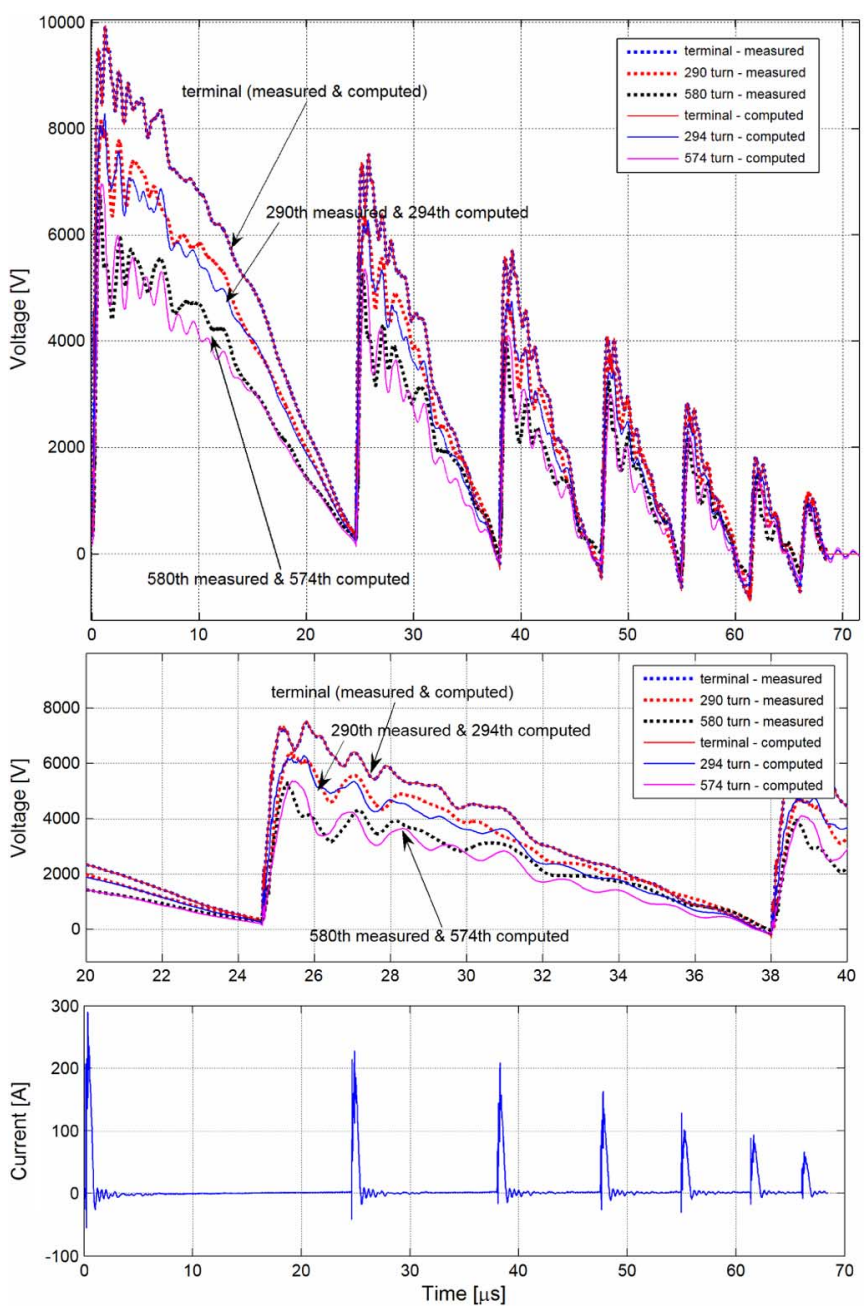

Fig. 16. Measured and computed voltages in phase B (upper figure); increased time scale (middle figure); measured circuit breaker reignition current (lower figure); source voltage is $8 \mathrm{kV}$.

that connects the circuit breaker and transformer. In this case, the voltage escalates more than in the case when a cable exists between the VCB and transformer.

Fig. 17 is a similar example for a case when the supply voltage is $12 \mathrm{kV}$.

\section{DISCUSSION}

Transformer characteristic is measured for open and shortcircuited LV winding. In each of them, two impedance amplitude and phase values are determined. These values correspond to the resonance frequencies of the cable.

Figs. 18, 19, and 20 show measured amplitude and phase terminal impedance characteristics of the transformer, the busbar and the cable used in the test circuit of Fig. 7.

The ratio between the terminal transformer voltage and the supply voltage can be approximately determined by

$$
k \approx \frac{Z_{\mathrm{tr}}}{Z_{\mathrm{tr}}+Z_{\mathrm{bus}}+Z_{\mathrm{cab}}}, \quad U_{T}=k \cdot U_{S} \sqrt{2}
$$

where $U_{T}$ is the maximum transformer terminal voltage, and $U_{S}$ is the rms value of supply voltage. In (7), absolute values of the impedances are used. 

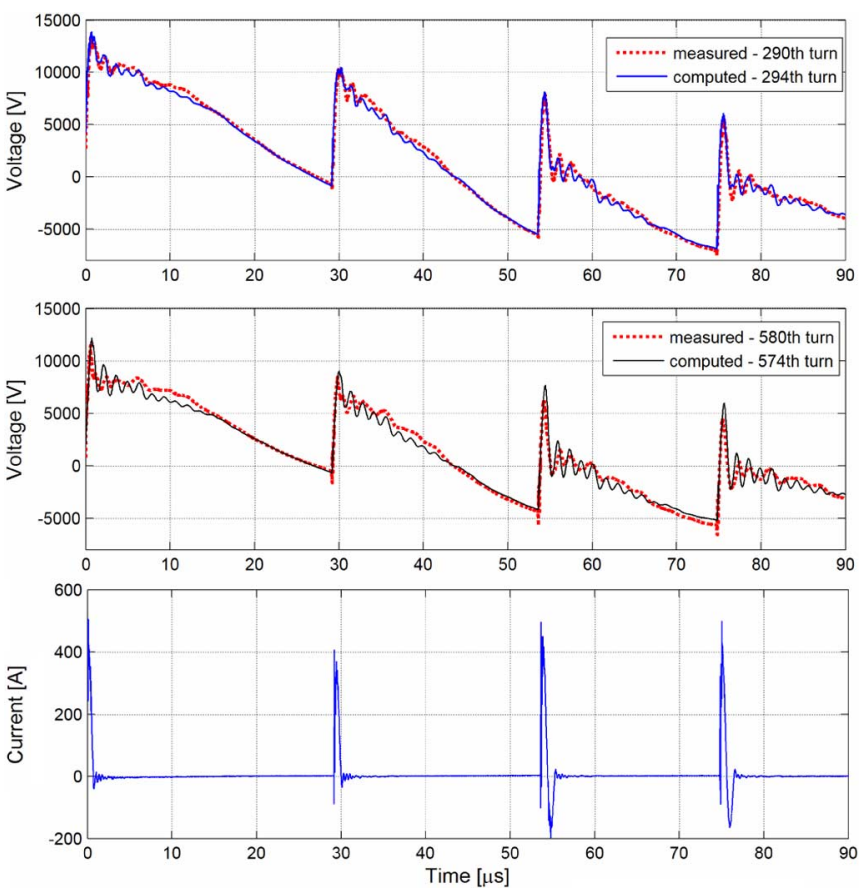

Fig. 17. Measured and computed voltages of 290th and 294th turn in phase $\mathrm{B}$ (upper figure); measured and computed voltages of 580th and 574th turn in phase B (middle figure); measured circuit breaker reignition current (lower figure); source voltage is $12 \mathrm{kV}$.
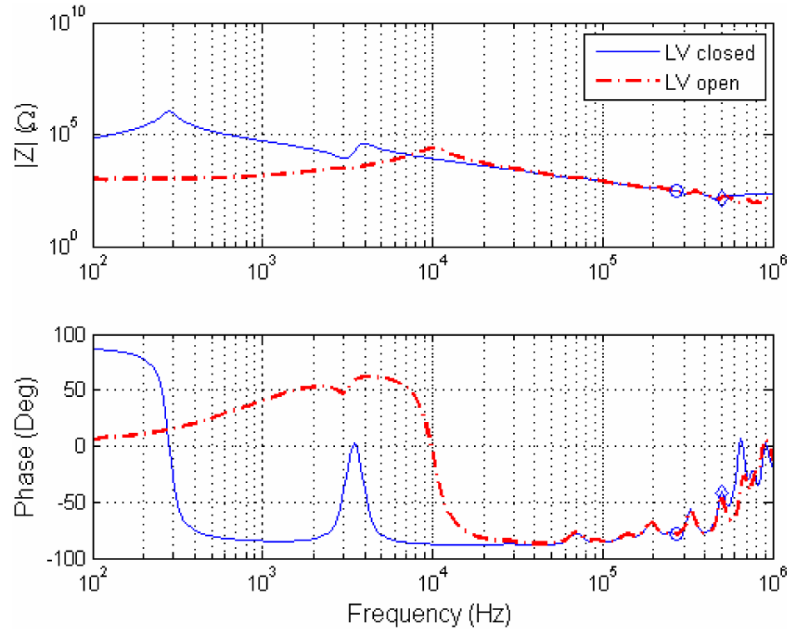

Fig. 18. Transformer terminal impedance characteristic; amplitude characteristic (upper figure); phase characteristic (lower figure).

Table IV shows the terminal impedances of the transformer, the busbar and the cable at cable's resonance frequency computed from the measured characteristics. The frequency of the prestrike current is approximately $280 \mathrm{kHz}$, so the voltage division factor is $k=0.378$. For source voltages $6 \mathrm{kVrms}$ and $8 \mathrm{kVrms}$, the calculated maximum transformer voltages are $3.2 \mathrm{kV}$ and $4.26 \mathrm{kV}$ respectively. This approach explains why the maximum terminal transformer voltage increases slightly with the increase of the supply voltage when a cable is applied between the transformer and the circuit breaker.

After the prestrike current is cleared, transformer terminal voltage oscillates with a frequency of $500 \mathrm{kHz}$. From Fig. 20,
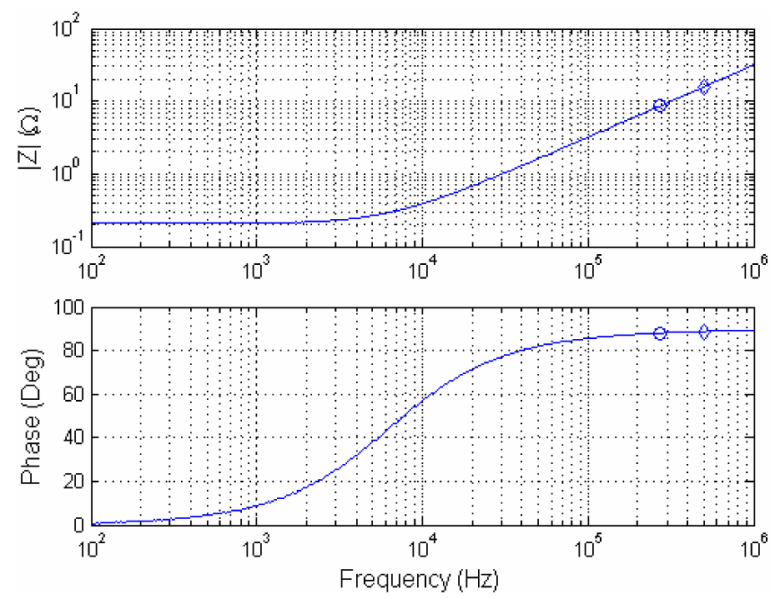

Fig. 19. Bus-bar terminal impedance characteristic; amplitude characteristic (upper figure); phase characteristic (lower figure).
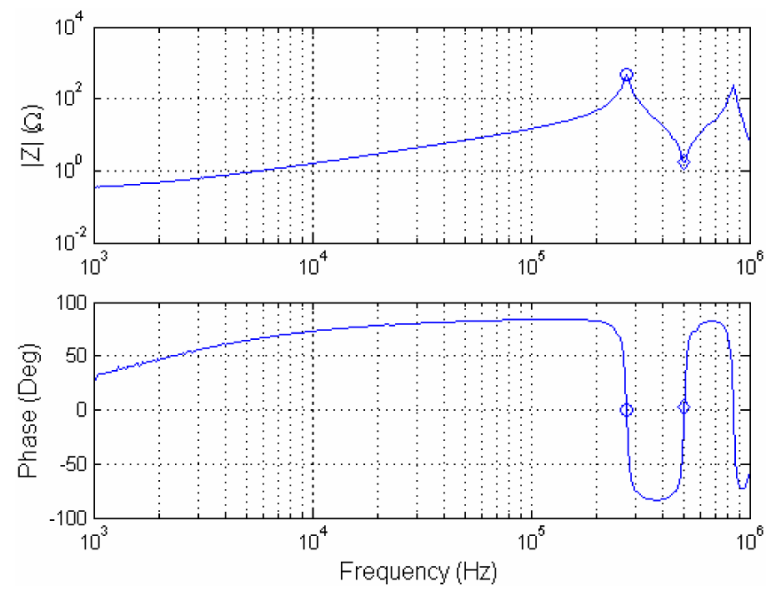

Fig. 20. Terminal impedance characteristic of the cable (receiving end of the cable short circuited); amplitude characteristic (upper figure); phase characteristic (lower figure).

TABLE IV

MEASURED IMPEDANCES AT SPECIFIC RESONANCE FREQUENCIES

\begin{tabular}{|l|c|c|}
\hline \hline Frequency & $\sim 280 \mathrm{kHz}$ & $\sim 500 \mathrm{kHz}$ \\
\hline$\underline{Z}_{t r}$ & $58.86-\mathrm{j} 280.9$ & $103.11-\mathrm{j} 90.7$ \\
\hline$\underline{Z}_{b u s}$ & $0.29+\mathrm{j} 8.65$ & $0.334+\mathrm{j} 15.89$ \\
\hline$\underline{Z}_{c a b}$ & $463-\mathrm{j} 0.085$ & $1.73+\mathrm{j} 0.0925$ \\
\hline
\end{tabular}

it can be seen that this frequency is the second resonance frequency of the cable. So, the frequency of the transformer terminal voltage depends on the transformer equivalent inductance and capacitance, and the busbar inductance at this frequency. From Fig. 19, the busbar inductance at $500 \mathrm{kHz}$ is estimated as $5 \mu \mathrm{H}$. Taking into account a transformer bushing capacitance of approximately $1 \mathrm{nF}$, and making use of the measured transformer impedance from Table IV, one can easily derive a transformer inductance of $72.5 \mu \mathrm{H}$. This implies a frequency of $591 \mathrm{kHz}$.

Fig. 21 shows two different tests of measured voltages at different turns along transformer windings in phase $\mathrm{B}$ and phase $\mathrm{C}$. 

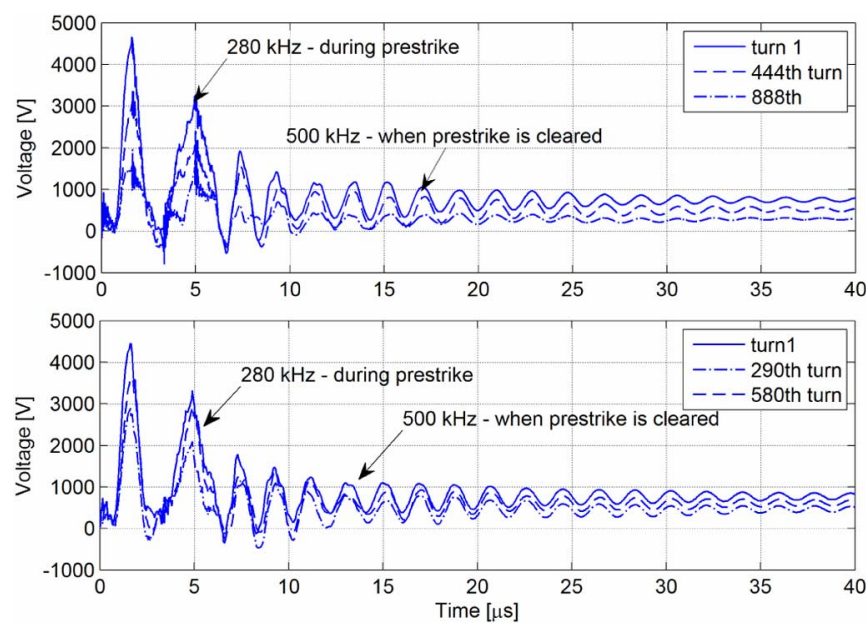

Fig. 21. Voltage distribution along the transformer winding for applied voltage of $8 \mathrm{kV}$. Upper figure-phase C. Lower figure-phase B.

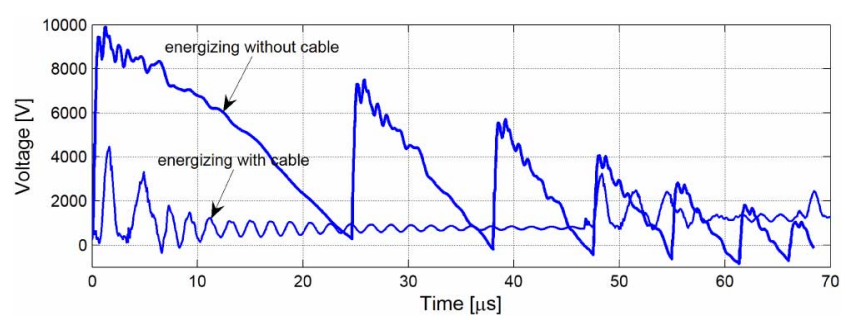

Fig. 22. Comparison between measured transformer terminal voltages when the transformer is energized with and without a cable; source voltage is $8 \mathrm{kV}$.

It can be seen that the frequency of the voltage oscillations after the prestrike current is cleared is the same, and it is also around $500 \mathrm{kHz}$. Therefore, using Fig. 5 another simplified analysis of the oscillation frequency of the internal voltages is done. One $L$ in parallel with $C_{1}$ leads to a frequency of $650 \mathrm{kHz}$. However, in this approximation no influence from the mutual inductances that correspond to the inductance matrix $\mathbf{L}$ is taken into account.

This implies that the actual frequency will be much lower than $650 \mathrm{kHz}$. Furthermore, a linear distribution of the voltage amplitudes can be seen. Fig. 22 shows the measured transformer terminal voltage with and without a cable. The amplitude of the voltage during prestrike when a cable is applied is less than the half of the voltage amplitude when the transformer is energized without a cable.

\section{CONCLUSION}

Transformers can be exposed to very fast voltage transients which occur due to prestrike or restrike effect of the circuit breaker. Transformer insulation will deteriorate and finally fail when the transformer is frequently exposed to these transients. Surge voltages are dangerous not only with their amplitude but also with their rate of rise. Therefore, in order to design the transformer insulation, it is important to simulate the voltage wave forms more accurately. Especially, the voltage escalation during prestrikes or restrikes has very high rate of rise, and therefore an accurate transformer model is important. In this work, switching tests are done with and without a cable connected between the circuit breaker and transformer.
From the results, it can be seen that the case when a cable exists is different from that when no cable exists. The cable contributes to longer frequency oscillations and lower voltage amplitudes, whilst switching the transformer without cable will contribute to steeper voltage rise and short duration of the restrike current.

This work shows that the lumped-parameter model based on discrete telegraphist's equations can be used with full success to study voltage transients along transformer windings. The modeling needs only information about the geometrical dimensions of the transformer which can be easily obtained by the manufacturer.

\section{ACKNOWLEDGMENT}

The authors thank Pauwels Transformers, the High Current Laboratory at the Eindhoven University of Technology, Nuon Tecno, and KEMA High-Power Laboratories for providing the necessary equipment and for using their facilities. The help for performing measurements of fast transients provided by Ir. R. Kerkenaar and Ing. Rene van Hoppe is highly acknowledged. The authors also thank Dr. A. P. J. van Deursen for his valuable suggestions throughout this project.

\section{REFERENCES}

[1] B. K. Gupta, E. P. Dick, A. Greenwood, M. Kurtz, T. S. Lauber, B. A. Lloyd, A. Narang, P. R. Pillai, and G. C. Stone, Turn Insulation Capability of Large AC Motors Vol. 2 Appendixes: Final Report Tech. Rep. EPRI-EL-5862-Vol.2, 1988.

[2] G. Stein, "A study of the initial surge distribution in concentric transformer windings," AIEE Trans., pp. 877-892, Sep. 1964.

[3] G. C. Damstra:, "Virtual chopping phenomena switching three-phase inductive circuits," in Colloq. CIGRE SC 13, Helsinki, Finland, Sep. 1981.

[4] W. M. C. van den Heuvel and J. E. Daalder, Interruption of a Dry Type Transformer in No-load by a Vacuum Circuit Breaker Eindhoven, The Netherlands, EUT Rep., 1983.

[5] A. O. Soysal, "Protection of arc furnace supply systems from switching surges," in Proc. IEEE PES Winter Meeting, New York, 31 Jan.-4 Feb. 1999, vol. 2, pp. 1092-1095.

[6] J. Kosmac and P. Zunko, "A statistical vacuum circuit breaker model for simulation of transient overvoltages," IEEE Trans. Power Del., vol. 10, no. 1, pp. 294-300, Jan. 1995.

[7] Cigre SC A3: Electrical Environment of Transformers-Impact of Fast Transients Summary Paper of the CIGRE JWG 12/32/23.21, A3-04 (SC) 26 IWD.

[8] M. Popov, L. van der Sluis, and G. C. Paap, "Investigation of the circuit breaker reignition overvoltages caused by no-load transformer switching surges," Eur. Trans. Electric Power (ETEP), vol. 11, no. 6 , pp. 413-422, Nov./Dec. 2001.

[9] E. Colombo, G. Costa, and L. Piccarreta, "Results of an investigation on the overvoltages due to a vacuum circuit breaker when switching an H. V. Motor," IEEE Trans. Power Del., vol. 3, no. 1, pp. 205-213, Jan. 1988.

[10] J. L. Guardado and K. J. Cornick, "A computer model for calculating steep-fronted surge distribution in machine windings," IEEE Trans. Energy Convers., vol. 4, no. 1, pp. 95-101, Mar. 1989.

[11] J. L. Guardado, V. Venegaz, E. Melgoza, K. J. Cornick, and J. L. Naredo:, "Transient overvoltages in electrical motors during sequential pole closure," IEEE Trans. Energy Convers., vol. 14, no. 4, pp. 1057-1064, Dec. 1999.

[12] J. L. Guardado, V. Carrillo, and K. J. Cornick:, "Calculation of interturn voltages in machine windings during switching transients measured on terminals," IEEE Trans. Energy Convers., vol. 10, no. 1, pp. 87-94, Mar. 1995.

[13] Y. Shibuya, S. Fujita, and N. Hosokawa, "Analysis of very fast transient overvoltages in transformer winding," IEE Proce. Gener., Transmiss., Distrib., vol. 144, no. 5, pp. 461-468, Sept. 1997.

[14] M. Popov, L. van der Sluis, G. C. Paap, and H. de Herdt, "Computation of very fast transient overvoltages in transformer windings," IEEE Trans. Power Del., vol. 18, no. 4, pp. 1268-1274, Oct. 2003. 
[15] B. Gustavsen and A. Semlyen, "Rational approximation of frequency domain responses by vector fitting," IEEE Trans. Power Del., vol. 14, no. 3, pp. 1052-1061, Jul. 1999.

[16] B. Gustavsen, "Computer code for rational approximation of frequency dependent admittance matrices," IEEE Trans. Power Del., vol. 17, no. 4, pp. 1093-1098, Oct. 2002.

[17] D. J. Wilcox, "Theory of transformer modelling using modal analysis," IEE Proc. C, vol. 138, no. 2, pp. 121-128, Mar. 1991.

[18] J. P. Bickford, N. Mullineux, and J. R. Reed, Computation of Power System Transients. London, U.K.: IEE/Peter Peregrinus, 1976.

[19] R. C. Degeneff, W. J. McNutt, W. Neugebauer, J. Panek, M. E. McCallum, and C. C. Honey:, "Transformer response to system switching voltage," IEEE Trans. Power App. Syst., vol. PAS-101, no. 6, pp. 1457-1470, Jun. 1982.

[20] W. J. McNutt, T. J. Blalock, and R. A. Hinton, "Response of transformer windings to system transient voltages," IEEE Trans. Power App. Syst., vol. PAS-93, pp. 457-467, 1974.

[21] R. C. Dugan, R. Gabrick, J. C. Wright, and K. V. Pattern:, "Validated techniques for modeling shell-form EHV transformers," IEEE Trans. Power Del., vol. 4, no. 2, pp. 1070-1078, Apr. 1989.

[22] Y. Shibuya and S. Fujita:, "High frequency model of transformer winding," Elect. Eng. Jpn., vol. 146, no. 3, pp. 8-15, 2004.

[23] High-Voltage Switchgear and Control Gear Part 110 IEC 62271-110, Inductive load switching.

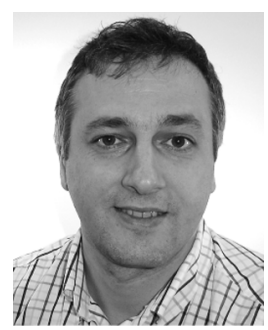

Marjan Popov (M'95-SM'03) received the Dipl.-Ing. and M.S. degrees in electrical engineering from the Sts. Cyril and Methodius University, Skopje, Macedonia, in 1993 and 1998, respectively, and the Ph.D. degree from Delft University of Technology (TU), Delft, The Netherlands, in 2002.

In 1997, he was an Academic Visitor at the University of Liverpool, Liverpool, U.K. Currently, he is with the Faculty of Electrical Engineering, Technical Mathematics, and Informatics, TU Delft, where he is an Assistant Professor in the Electrical Power Engineering group. He participates in Cigre SC B5 and WG Cigre A2/C4. His major fields of interest are arc modeling, transients in power systems, parameter estimation, relay protection and renewable energy.

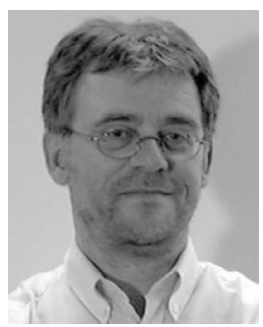

René Peter Paul Smeets (M'95-SM'02-F'08) received the M.Sc. degree in physics from the Eindhoven University of Technology, Eindhoven, The Netherlands, in 1981 and the Ph.D. degree (for research on vacuum arcs) from Eindhoven University, Eindhoven, The Netherlands, in 1987.

He was an Assistant Professor with Eindhoven University until 1995. During 1991, he was with Toshiba Corporation's Heavy Apparatus Engineering Laboratory, Kawasaki. Japan. In 1995, he joined KEMA, Arnhem, The Netherlands. At present, he manages the R\&D activities of KEMA's High Power Laboratory. In 2001, he was appointed Part-Time Professor at Eindhoven University of Technology.

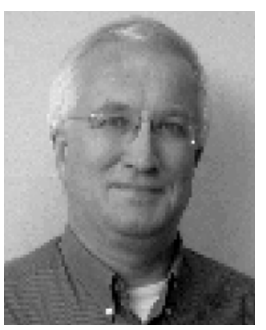

Lou van der Sluis (M'81-SM'86) was born in Geervliet, The Netherlands, on July 10, 1950. He received the M.Sc. degree in electrical engineering from Delft University of Technology (TU), Delft, The Netherlands, in 1974.

He joined the KEMA High Power Laboratory, Arnhem, The Netherlands, in 1977 as a Test Engineer and was involved in the development of a data acquisition system for the High Power Laboratory, computer calculations of test circuits, and the analysis of test data by digital computer. In 1990, he became a part-time Professor and since 1992 has been a full-time Professor at the TU Delft in the Power Systems Department. He is a Past Chairman of CC-03 of Cigre and Cired to study the transient recovery voltages in medium and high voltage networks.

Hans De Herdt was born in Rumst, Belgium, on October 7, 1964. He received the M.Sc. degree in electrical-mechanical engineering in 1987 from the Katholieke Universiteit Leuven, Leuven, Belgium.

In 1989, he joined Pauwels Trafo Belgium, Mechelen, where he is currently a R\&D Project Engineer. His main interests are electromagnetic field calculations, transient overvoltages, and transformer modeling.

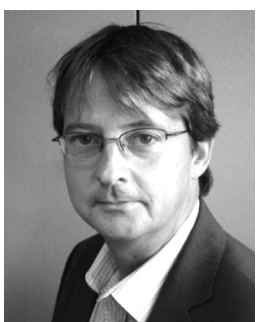

Jan Declercq (M'98) received the Master's degree in mechanical engineering, the M.B.A. degree, and the $\mathrm{Ph} . \mathrm{D}$. degree in fluid dynamics and heat transfer, all from the Katholieke Universiteit Leuven, Leuven, Belgium.

After a sabbatical leave at Purdue University, West Lafayette, IN, in 1996 he joined Pauwels Trafo Belgium, Mechelen, an international transformer manufacturer. He has been Head of the Research and Development Department since December 1999, and is now active as a Business Development Manager of New Technologies. His main responsibilities are research, technological risk assessment, new materials and new applications, marketing of new developments, and international business development for wind energy. He is a member of and active in different working groups of IEEE, IEC TC 14, Cigre A2, and EWEA committees. He is currently cCnvener of Cigre A2-WG24 Thermal Performances. His interests are heat transfer, fluid dynamics, acoustics, and renewable energy. 